thing otherwise resembling beak or bird; and the chick may repeat it hundreds of times in spite of failure thus to obtain food. It is even possible to evoke a "supernormal" response by exaggerating the feature ; and in this regard the author cites woman's use of lipstick as an analogy.

Much that is most puzzling in the behaviour of birds becomes explicable in terms of 'displacement activities', in accordance with what Edmund Selous long ago called "the law of the interchangeability of energies". When an urge is frustrated, it finds an outlet in some action belonging to quite a different context-like the cat, suddenly unsure of itself, which stops to wash its face. These irrelevant actions are often characterized by being incomplete and may become stereotyped in a ritual form. Actions of this type make up a large part of the behaviour of birds, and not least in those species which are markedly social in the reproductive phase of their lives.

The interesting explanation is offered of the pair's defence of 'territory' around the nest, in the case of a colony on open ground, that dispersion adds to the value of the cryptic coloration of eggs and young. The observed effect of predation is indeed a wider spacing of the nests when the birds lay again.

Dr. Tinbergen frankly enjoys wresting secrets from the living things which he studies. He likens his pleasure to that of the chase: "I am not in the least ashamed," he says, "to confess that my photographs and this book are my trophies." Many will gain by examining them.

LANDSBOROUGH ThOMSON

\section{NATURAL HISTORY OF THE PINKFOOT GOOSE}

\section{A Thousand Geese}

By Peter Scott and James Fisher. Pp. $240+17$ plates. (London : William Collins, Sons and Co., Ltd., 1953.) 21s. net.

T

HE late Gino Watkins once quoted to us : "When a man really wants to do a thing, he will succeed". Peter Scott certainly demonstrates the fundamental truth of this seemingly sweeping statement. Urged by a deep-rooted interest in water fowl, almost bordering on an obsession, he has managed to bring together a unique collection of live Anatidae on the New Grounds near Slimbridge, has travelled widely for the purpose of collecting and observing out-of-the-way species, and has recently embarked on a very ambitious population study of the pinkfoot, a goose wintering mainly in Britain and breeding in the Arctic. This idea was conceived at a time when it was not yet known for certain where the main breeding colonies of the species were.

At first, in the late 'forties, the geese were captured (with the now famous rocket-net technique), ringed and otherwise marked on various wintering grounds in England and Scotland; but in 1950 Scott decided to go to the heart of Iceland where, he had strong reasons for believing, the largest breeding colonies must be found.

Together with Miss Philippa Talbot-Ponsonby (now Mrs. Scott), the well-known Icelandic ornithologist Finnur Gudmundsson, and James Fisher he set out in June 1951, and in the beginning of August returned, having found the large colonies which he knew must be there, having made provisional counts, and having ringed 1,151 geese -a remarkable achievement.

"A Thousand Geese" is the narrative of this expedition, written in a simple, straightforward style, which brings out the atmosphere of such a delightfully single-purposed enterprise, during which a man, while working hard, can get a good mental rest by living close to Nature.

In a footnote at the end of the book Scott adds that he went again in 1953 and that this time, using the experience gained in 1951, he caught 9,005 geese. According to his estimates about "one in five of the world pinkfoot population now carries a ring". The repeated sampling makes calculations of the Iceland population possible, and the large-scale ringing will provide valuable data on various aspects of pinkfoot population ecology. Excellent planning, great tenacity of purpose, and exceptional skill has enabled him to make this admirable start.

Apart from the story, the book contains, in an appendix, detailed information on the status of the pinkfoot in Spitsbergen, on its status in Greenland, notes on the birds observed at the camp site, a list of plants found (compiled by Gudmundsson), estimates of the local pinkfoot population, and a bibliography of the breeding distribution of the species.

The illustrations are excellent, and special mention should be made of the very attractive book-jacket.

\section{N. TINBERGEN}

\section{A HANDBOOK FOR BIRD- RINGERS}

Bird-Ringing

The Art of Bird Study by Individual Marking. By R. M. Lockley and Rosemary Russell. Pp. viii +119 +8 plates. (London: Crosby Lockwood and Son, Ltd., 1953.) 9s. $6 d$. net.

$\mathrm{R}$ M. LOCKLEY is a pioneer of British bird observatory work, and few ornithologists can have exceeded his total of birds personally ringed. $\mathrm{He}$ also has many European correspondents in this field, and his collaborator, Mrs. Russell, has had recent experience of North American 'banding' methods. Their first three chapters are written most entertainingly and describe the history, value and technique of bird-ringing succinctly but with interesting illustrations. At the same time, there is a needed emphasis on care. Bird trepping and ringing have become enormously popular in recent years and have attracted a large number of enthusiasts with little previous knowledge of ornithology. But birds are delicate organisms, and it is essential scientificallyas well as most desirable on humane grounds-that they should be caused as little discomfort as possible when they are caught and afterwards handled.

More than half the book is taken up with illustrated descriptions of traps and other catching devices. This is quite reasonable. Provided the need for care and gentleness is realized, the actual process of ringing a bird is simple and, in any event, can only be learnt in the field. The real art lies in catching the bird. Most of the designs have already appeared in the first field guide of the British Trust for Ornithology (1950) by P. A. D. Hollom, but the authors have various developments and modifications to record and add some useful American patterns excluded by the Trust's booklet. 